\title{
Teaching Empirical Methods: Critical Reflection on Class Design and Blended Learning and Results of a Case Study on Competence Management
}

\author{
Covarrubias Venegas, Barbara, \\ FHWien University of Applied \\ Sciences \\ Institute for Human Resources \\ and Knowledge Management
}

\author{
Gaedke, Gudrun \\ FHWien University of Applied \\ Sciences \\ Institute for Human Resources \\ and Knowledge Management
}

Geyer-Hayden, Barbara

HowKnow e.U.

\begin{abstract}
This paper reflects how class design and blended learning can be implemented by teaching scientific research methods to part-time students. The aim of this study was to introduce students to scientific research methods within a one year project and determine the attitudes of the volunteers towards a web-based competence. This case study follows an exploratory design with qualitative and quantitative steps. High motivation towards skills representation and providing competencies within expert groups could be identified, if data protection is guaranteed.
\end{abstract}

\section{Introduction}

This research project was undertaken by a group of part-time Bachelor Students under the supervision of the authors. The didactical concept of this course is to provide students with experience in empirical research doing a project with qualitative and quantitative steps on their own and analyzing the implications for the case study organization. This research is an exploratory case study design.

According to Aguado a course that stresses the "hands-on" approach should teach students how research is conducted, but it also should require them to do the research, as a way of communication the importance of empiricism in the social science [1]. Both instructors and students can benefit from this teaching strategy. It gives the instructor an opportunity to integrate research with teaching, and to inject students directly into an active research agenda.

Our experience with teaching empirical research within a two semester project is that students more easily understand the idea and importance of scientific research in the Human Resource field. As
Ball and Pelco describe many instructors include active - learning experiences in their researchmethods courses [4]. Student-developed research projects involve original research conducted by a single student or a small group of students. Research projects provide a wonderful active-learning experience that students typically embrace with increased motivation and interest.

Aguado (2009) highlights that many students possess very weak foundation for conducting empirical research. Empirical research is different from most of the other "research" that many students have completed. This deficit makes it a challenging undertaking that can lead to frustration for both the instructor and the students. The experience which will be described in this article help avoid these situations.

\section{Statement of article purpose}

At the beginning of the semester the students assigned to the groups. According to Ball and Pelco, a fundamental goal of the class is to encourage consistent and optimal involvement of every student in each group. On method recommended to achieve this goal requires students to provide peer assessment of their fellow group member. This was an important element of the final grade.

In the fall semester the student group started to explore the theoretical context. Same as Aguado the lecturer provided the students with citations and background reading for the topic. Also students learned how to conduct literature reviews by using peer-reviewed articles. The first steps were to draft the research questions and to develop an interview structure for a partially structured interview questionnaire. As Aguado described the intructors must find a way of conveying to students the importance of asking an appropriate social-scientific 
question. The students carried out the interviews and were also responsible for the transcription of those. Last, but not least they analyzed the interviews with categorization and paraphrasing the texts and prepared the final report as well as a presentation for the organization.

In the summer semester the students continued with the results of the qualitative research project by formulating hypotheses and defining the sample. As a following step they designed the questionnaire for the online tool and carried out the survey (including reminders). The data analysis and interpretation in SPSS statistics was done partially together with the supervisors. As described by Aguado, the goal of this particular research-methods course is to communicate the research process by using a very practitioner-oriented method that includes data gathering, analysis via a statistical software package (SPSS), and learning the language of social-science research. The project ended with a presentation for the client.

Similar to Barraket students consistently indicated that formal presentation of technical material and disciplinary insights by the lecturer was a very important part of their comprehension and learning in this subject [5]. What appeared to make the transmission of this information more effective, however, was the use of group exercises and primary source material that allowed students to build a common experience from which to draw concrete examples and to which they could relate specific dilemmas.

With the lessons learned from the project the students may use their knowledge for further research assignments and professional purposes. As Aguado described understanding empiricism and the systematic analysis of data was an important lesson conveyed to the students in this class, because they saw how this step creates the basis of good socialscience research.

The advantages of this approach are in line with Barraket [5]. The classroom experience was characterized by a high level of dialogue and interaction, the assessment results suggest overall strong engagement with the subject matter, and student feedback was very positive. One of the key strengths of this approach was that it allowed students to build common experimental ground, which provided a shared base for engaging with more technical aspects of the subjects matter.

In addition, as described by Ball and Pelco, this approach incorporates recent pedagogical and technological innovations and students respond well to the challenges posed by such a class format [4]. Moreover this teaching format is more interesting and stimulating to teach than the traditional lecturetext format.

\section{Changes in Class Design}

In the past years the class was divided into three groups. Each team worked on their own (sub) project and was supervised by a lecturer. According to Ball and Pelco, the group project approach ensures a deeper understanding of the research process. There were different scenarios for the client of the group: an external customer for all three groups, three different external clients and a common internal client. Aguado is seeing this way to structure a research-methods class so that the students gain a practial knowledge of how research in done. The goal of the course is to communicate the research process by using a very practitioner-oriented method that includes data gathering, analysis via a statical software package and learing the language of socialscience research.

Now the authors use less time for the presentation of the theoretical content. Ball and Pelco note that the complexity of the course materials in research methods courses are quit high while students' interest in this material can unfortunately be quite low. But the lecturer presentations are followed by examples of past years projects. Real life examples have proven to be easier for students to understand than the theory. Normally it is difficult to construct real-world examples. In this case, the lecturer had the opportunity to draw on projects from previous years. Therefore, concrete examples from the previous projects were added to the online course materials. These documents are examples of paraphrasing, evaluation and final report. Questions and discussions with the students mostly arise on basis of the practical examples

Over the years the focus has been placed on the quality of content. This was achieved through a series of measures. The groups were given more time for creating the content. The students were encouraged to give each other feedback on the evaluations and interpretations (before the supervisor has given his feedback). In the elaboration of specific, relevant statements and scientific questions, the students needed more support from the lecturers. Concerning to Aguado, the instructor must find a way of conveying the students the importance of asking an appropriate social-scientific question; learning how past researchers have addressed an issue; collecting data; and learning how the interpret cryptic statistical output. Not enough time and attention to the main statements can produce poor results.

As described by Ball and Pelco, the majority of class time is taken up with group discussion, and the instructors act as "floating facilitators". After the first evaluation a group once said, we have found no relevant new statements from the interviews. Only a joint discussion, interpretation and evaluation of the outcome have led to tangible meaningful statements. 
For others, it was difficult to formulate in scientific language, or to answer the research questions. On all these points an intensive care by the supervisors was necessary. This not only ensures the quality of results but also the learning success of students. According to Barraket, the pedagogical challenge is one of moving away from a standard didactic approach of transferring technical information about research methods to students, to the creation of an interactive environment in which students are able to master that technical information through processes of communication, experience, reflection and collective analysis [5].

To put a focus on content creation and feedback the timing of the course was changed. First, the teaching units were distributed throughout the semester immediately then most events were held at the beginning and at the end of the semester. If the project has an external client, the students need more time to coordinate decisions and to present results.

There were also changes in the coordination of group members. First, the team was left to itself, then the project management was performed by the supervisor. Meanwhile, the group chooses a project manager who is responsible for the distribution of tasks. However, it has proven that the division of tasks is performed in the course and is accompanied by the lecturer. The results of this process are documented in the Wiki.

\section{Blended Learning}

The participants of the course are part-time students. Group work outside the presence dates are difficult for them. But less difficult if the job is shared within the course in sub-tasks for each student and the tasks can be handled online.

Fearon, Starr \& McLaughlin [7] also highlight that many students have to balance work and study commitments, so blended learning is an ideal way of receiving and disseminating key teaching, or lecture material.

All teaching materials are available online and each group was given a forum and a wiki. The supervisors therefore have different experience in using these tools for teaching.

The groups used the forum to send messages. It was used as a replacement for e-mail because the messages are archived and comprehensible. Unlike the forum, the wiki has no notification mechanism. Therefore, the two tools have supplemented. The wiki-based materials provide not only the collective knowledge in a course but also provide a chronological history as the knowledge base as it evolved [11].

The supervisors gave the students a brief introduction to the wiki. Then they used the wiki, especially for the collaborative creation of content. From a teaching perspective, the wiki model facilitates a cognitive information processing model of learning [11]. For example, to create the interview guidelines, documentation of tasks, uploading the interviews and transcripts. It has been shown that the wiki is suitable for some tasks better and fewer for others.

The wiki can be used for teaching scientific research methods in a blended learning setting. A group can formulate the questionnaire in the wiki together. This is mainly for documents of which there are many different versions. The supervisor can then see who wrote what question. Minocha \& Roberts point out that this function is particularly useful for assessment [12].

In a table in the wiki, the division of tasks, such as lead and evaluate interviews, are documented and tracked. Documents such as transcripts can be uploaded to the site. Students learn social media skills through the use of wikis and practice them.

According to Fearon, Starr \& McLaughlin blended learning should be used as an integral part of a new teaching and learning strategy that enables graduates to meet key challenges for working in the twenty-first century [7].

But the use of wikis has its drawbacks. Simultaneous work on a site does not work. This means that the wiki is suitable for tasks from home but not in the classroom. That means that a wiki tool complements a face-to-face collaboration with a mechanism to collaborate remotely and asynchronously on a written product [11]. Most students have to learn to deal with the wiki which means an additional expenditure of time.

Between the various wikis, there are differences in the usability. Therefore, the selection of the appropriate wikis for teaching is important. A further disadvantage is the lack of notifications on changes to the supervisor.

The disadvantages of wikis found in the course were also described in the literature [12]. The students had to keep going back to the wiki to check if any new contributions by other group members had been made. Further, they felt that a wiki might become unusable and unmanageable for a large project. The empirical results of the case study will be presented in the following chapters.

\section{Main research questions}

The goal of the competence management system which the Austrian Red Cross (ARC) Lower Austria plans to introduce is finding the best-fitted people for a specific task or job. This takes place through a selective search in the skill database, thereby using the volunteer's competencies as effectively as possible. The aim of this qualitative study was to determine the attitudes of the employees towards such a system and under which conditions they 
would put such a system to use. Hence, the following research question was derived:

What motivates or inhibits the volunteers of the Red Cross of Lower Austria, to use a "self-service" system for detecting their skills?

In a further step, five research areas were identified against which the attitudes of the volunteers were analyzed:

- What do volunteers perceive as benefits of such a competence database (professional, personal)?

- What is the professional, personal and external motivation for volunteers of the Red Cross Lower Austria?

- What skills (from other colleagues or their own) would they introduce into the database?

- Does the IT application (knowledge, experience) influence the possible use of the database?

- How important is system usability (readiness conditions, privacy, rights) for the implementation process?

\section{Competence Management}

Competence Management has the aim of generating competencies that provide the organization with the right mix of talent to meet existing and future needs and can be considered as a practice that becomes more and more important in private and public organizations [3], [14]. It helps not only to identify the right person for a job position, but also performing succession plans, training analysis and other functions of the Human Resource Management Department [6].

Non Profit Organizations (NPO's) create in all areas of society charitable services. To fulfill its ideological objectives they have to provide services, building on an appropriate knowledge potential. This is influenced largely by the organizational knowledge and skills data base (Andeßner 2006). Heinsman et al. [8] highlight the important contribution at organizational level, as the key knowledge that an employee or an organization possess are displayed. New possibilities of the "selfservice” routine, whereby employees themselves are responsible for registering and maintaining their competencies via a web module and the challenges of implementation of such a module are widely unexplored [6], [9].

\section{Implementation of the development work}

This chapter describes briefly the research design and methodology.

The ARC Lower Austria was interested in the attitude of volunteers towards a web-based competence management system, especially since the volunteers themselves maintain this system.

In order to identify motivating factors as well as obstacles, an interview guide was developed. Eight interviews were conducted over a two-month period (October/November 2010), using semi-structured interview methods. The interviews lasted from one to two hours and were taped and transcribed. The transcripts were then e-mailed to the interview subjects for verification and adjustments. The interview questions focused on motivational factors but also on possible obstacles. The results gave a deeper insight and based on the results a quantitative survey could be developed.

The online survey was administered in April 2011. The survey was pre-tested on a group of four volunteers of the ARC Lower Austria and four research assistants at the FHWien University of Applied Sciences. Following minor changes, the survey was mailed to all volunteers at the ARC Lower Austria through the responsible manager of the ARC Lower Austria. After two waves of mailing, 1493 responses were received and evaluated with PASW statistics 17.

\section{Discussion of results and conclusions}

In the following two chapters, the results of the qualitative and quantitative studies are discussed.

Author names and affiliations are to be centered beneath the title and printed in Times 12-point, nonboldface type. Multiple authors may be shown in a two- or three-column format, with their affiliations italicized and centered below their respective names. Include e-mail addresses if possible. Author information should be followed by two 12-point blank lines.

\subsection{Qualitative study}

Taking into account all aspects and results of the qualitative investigation, the following results can be described:

At the ARC Lower Austria, the interviewees are offered a wide range of developmental opportunities. Work for the ARC Lower Austria is seen as an additional field of activity, as well as a balance to everyday life. In addition, abilities and skills can be acquired or discovered that are applicable and useful in daily life.

The direct team is given a high priority; team spirit is strong, and personal contact is important. Hence, networks are developed, strengthened and used on both a professional and personal basis. Among interviewees, there was a general willingness to use web-based systems to announce their skills. As all of the interviewees' belonged to the younger generation, no conclusion about elderly workers and 
their attitude towards such web-based systems could be made.

Some personal, informal telephone networks have emerged that allow individuals to quickly and efficiently make contact. These phone systems have the advantage of providing interviewees with a quick and easy means of getting answers to questions as well as rapid support. This can be interpreted as an interest in having the opportunity to use web-based systems for support functions.

The activities at the ARC Lower Austria are regarded as meaningful and mind-expanding employees want to make a contribution to society. The general willingness to provide assistance and to work for others is strong. All of the interviewees specified that they would be willing to assist if the ARC Lower Austria contacted them to employ an announced special skill. But the interviewees stated clearly that they would not appreciate if professional skills were exploited by the ARC Lower Austria.

A system that supports the delivery of assistance that "helps helping" is likely to see positive response.

In addition to these relevant statements about a possible willingness to use a web-based competence management system, some barriers could be detected as well.

As all of the interviewees use a computer or the Internet every day, aspects such as user-friendliness and data protection are important to them. The embedding of such a competence management system within the Intranet of the ARC Lower Austria could be identified as positive.

Some interviewees addressed the topic of limiting right of access to the disclosed data. Trust seems to be very important. High trust level within the direct team and the district office could be identified, while the answers were formulated more cautiously concerning the central unit in Tulln. In general, throughout all interviews, emotional distance between regional volunteers vis a vis employees of the central unit in Tulln could be noticed. Whether this aspect depends on the geographical distance to the central unit in Tulln or whether there are other influential aspects could not be answered.

\subsection{Quantitative study}

Two-thirds of the respondents were male (68.7\%) and one-third female (31.3\%), while the majority of the respondents were between 21 and 30 years old (40.1\%). Other age groups are presented equally throughout the sample: younger than 21 years (13.8\%), 31 - 40 years (18.3\%), 41 - 50 years (14.6\%) and older than 50 years (13.3\%).

The majority of the respondents were nonmanagerial volunteers $(76.7 \%)$. Only a minority of $23.3 \%$ of the managerial staff participated in the study; this result derives from the organizational structure within the ARC Lower Austria. 71.2\% were respondents from district offices, 26.9\% from local offices and only $1.9 \%$ from the central unit in Tulln.

Attitude towards a web based competence management system and existing competencies within the ARC Lower Austria

Only $55.2 \%$ of the respondents were conscious that the ARC Lower Austria needs further competencies within the organization. The research team was aware of possible misunderstandings of the term "competencies" and so expected a bias. Therefore, a practical example of a volunteer who contributed his knowledge to the website design was explained at the beginning of the questionnaire. But the ARC still has the image of looking for people only with knowledge of first aid.

$84.4 \%$ of the respondents stated that they definitely/probably would contribute with special knowledge, while only $15.6 \%$ stated they probably would not/definitely would not. $90 \%$ of the respondents with managerial function would provide the competencies, while a slight slower number of respondents with non-managerial function would do so $(82,7 \%)$. A chi-square test showed that there is a highly significant statistical correlation between these two variables $(p<0,001)$. It could be proven as well, that the awareness of needs of "other" competencies and the attitude towards providing competencies to the ARC Lower Austria have a high significant statistical correlation $(\mathrm{p}<0,018)$; which means that it is very probable that the attitude towards providing "other" competencies is influenced by the awareness of the volunteers that the ARC Lower Austria needs such as well.

Table 1 shows the competencies the respondents stated possessing.

Table 1. Special competencies

\begin{tabular}{|l|r|}
\hline \multicolumn{2}{|l|}{ What special competencies do you have? } \\
\hline Organizational talent & $52.4 \%$ \\
\hline language knowledge & $43.4 \%$ \\
\hline $\begin{array}{l}\text { special manual skills (cooking, pipe } \\
\text { fitter knowledge, carpenter...) }\end{array}$ & $39.4 \%$ \\
\hline $\begin{array}{l}\text { special technical knowledge } \\
\text { (insurances, risk management...) }\end{array}$ & $29.1 \%$ \\
\hline $\begin{array}{l}\text { creative activities (painting, texting, } \\
\text { design,...) }\end{array}$ & $29.1 \%$ \\
\hline special IT skills & $24.8 \%$ \\
\hline $\begin{array}{l}\text { special professional education (event } \\
\text { management...) }\end{array}$ & $22.5 \%$ \\
\hline special knowledge (tourist guide...) & $16.7 \%$ \\
\hline $\begin{array}{l}\text { special expert knowledge (passive } \\
\text { energy...) }\end{array}$ & $13.5 \%$ \\
\hline
\end{tabular}

If the usefulness of such competence provision is clear (63.4\%), it is within reasonable limits (59.2\%) and there will not be additional "time burden" (30.2\%) the volunteers would provide their special knowledge.

As the ARC is a non-profit organization and the majority of the people delivering services for the ARC are volunteers without any financial reward, 
one question was asked about the willingness to contribute special knowledge without expecting any reward. $86.6 \%$ of the volunteers definitely/probably would provide their special knowledge without expecting reward for it.

The age group between 21 -30 years had the highest score (28.2\% do not expect reward), but was also the most represented age group in this question (40.1\%). In comparison, the volunteers 50+ represented with $13.3 \%$ in this question, had a relatively higher score of not expecting rewards (23.1\%).

An important part of the questionnaire explored the position of the volunteers towards their special competencies without certification/written proof. The aim of this section was to understand if the volunteers would tell and in a further step support the ARC with those competencies beyond first aid knowledge.

$67.2 \%$ of the respondents stated that they had existing knowledge without certification/written proof, but only $30.4 \%$ indicated that the ARC was aware of that special knowledge. Although there is no competence management system established it can be noticed that very few competencies without certification/written proof are known within the organization.

Table 2 shows who is familiar with the special knowledge.

Table 2. Familiarity with special knowledge

\begin{tabular}{|l|c|}
\hline \multicolumn{2}{|l|}{ Who is familiar with my special knowledge? } \\
\hline $\begin{array}{l}\text { colleagues on my shift know about } \\
\text { special knowledge }\end{array}$ & $72.4 \%$ \\
\hline $\begin{array}{l}\text { direct executive knows about special } \\
\text { knowledge }\end{array}$ & $52.0 \%$ \\
\hline $\begin{array}{l}\text { more colleagues know about special } \\
\text { knowledge }\end{array}$ & $67.0 \%$ \\
\hline $\begin{array}{l}\text { district office knows about special } \\
\text { knowledge }\end{array}$ & $49.8 \%$ \\
\hline $\begin{array}{l}\text { central unit in Tulln knows about special } \\
\text { knowledge }\end{array}$ & $9.5 \%$ \\
\hline
\end{tabular}

This leads to the conclusion that special knowledge is well known among colleagues, but as there is no formal competence database yet, the central unit in Tulln knows less about it.

Slight differences could be found between volunteers who stated that the ARC is aware of his/her special knowledge and those who stated the contrary in correlation to the attitude towards providing those competencies. Although the difference is small, but still highly significant statistically $(\mathrm{p}<0,001)$.

The previous results lead to the question of to whom volunteers would announce their special competencies. Our perception that the volunteers of the ARC Lower Austria feel neglected by the central unit in Tulln is supported by the low percentage $(22.7 \%)$ of the respondents who would announce their competencies to the central unit in Tulln.

\section{Expert groups}

The ARC Lower Austria has already implemented few expert groups (e.g. security expert group), but until now there have been no initiatives to proclaim their existence nor to publish results of their work. As the establishment of expert groups is a future task of Training and Development and the combination of the competence management database with expert groups is quite close, the following questions aimed at capturing the volunteers' attitudes in this regard. To give a shared understanding, this section of the questionnaire was initiated with a brief description of the term "expert group".

As described before, there are very few expert groups and they were never publicized, so the result, that only $19.8 \%$ of the respondents were aware of such an initiative is not surprising. The understanding of the term "expert group" included the following activities in descending ranked order:

Table 3. Understanding of an expert group

\begin{tabular}{|l|r|}
\hline \multicolumn{2}{|l|}{ What is your understanding of an expert group? } \\
\hline conceptual work & $81,3 \%$ \\
\hline work out overall solutions for the ARC & $71,0 \%$ \\
\hline exchange of knowledge & $66,1 \%$ \\
\hline collect and prepare knowledge & $60,4 \%$ \\
\hline advisory function & $58,7 \%$ \\
\hline $\begin{array}{l}\text { sensitization for current developments } \\
\text { within ARC }\end{array}$ & $36,1 \%$ \\
\hline $\begin{array}{l}\text { get to know likeminded colleagues } \\
\text { better }\end{array}$ & $22,4 \%$ \\
\hline effort in time and work related aspects & $22,7 \%$ \\
\hline
\end{tabular}

A very remarkable result for the project group was the answer to the following question: "Do you think that the assignment of expert groups is meaningful?" $94.4 \%$ of the respondents thought that the assignment of expert groups was very meaningful or rather meaningful. Therefore, it is not surprising that nearly $80 \%$ would consider participation in such an expert group (answers definitely/probably). One particular topic concerning expert groups is the frequency of meetings. It is evident that the frequency should be between monthly (32.8\%) or quarterly (41.9\%) meetings of the expert groups; those are the frequencies most respondents chose.

A reward system is of little importance/unimportant for $69 \%$, while for $96, \%$ the actual realization of the work of the expert group is very/moderately important. 83,3\% of the respondents stated that the local distance is very/moderately important. 
This leads to the conclusion that expert groups should be formed at a local level (e.g. districts) depending on one hand on the interests and competencies of the volunteers and on the other hand on the specific need of the organization.

\section{Data privacy}

The last questions treated the theme of data privacy as one of the important results of the qualitative study. In addition, the quantitative data showed that $81.5 \%$ of the respondents gave high importance (definitely or probably) to data protection, in terms of restricting access to a knowledge data base.

In advance we described that the volunteers of the ARC Lower Austria feel neglected by the central unit in Tulln and therefore only $22,7 \%$ would announce their competencies to the central unit in Tulln.

Table 4 shows a similar result as about $90 \%$ would agree that the local and district offices can see the announced competencies in the system, while only $64 \%$ stated that the central unit Tulln should be permitted so.

Table 4. Announced competencies in the system

\begin{tabular}{|l|r|}
\hline $\begin{array}{l}\text { What organizational level should be able to see the } \\
\text { announced competencies in the system? }\end{array}$ \\
\hline Local office & $86,5 \%$ \\
\hline District office & $87,7 \%$ \\
\hline Central unit Tulln & $64,6 \%$ \\
\hline
\end{tabular}

This leads to a question on organizational culture within the ARC Lower Austria, because only two thirds feel that the central unit Tulln should see their competencies. Individual data related to the competence management database must be kept confidential. The volunteers can access the specific information and forms using their unique username and password, but can only see and edit their own data. No other regulated member can normally see another volunteer's individual data.

\section{Adaptability of the results}

Competence management is a practice that becomes more and more important in private and public organizations, helping them to identify the right person for a job position, performing succession planning, training analysis and other core human resources functions [6], [10].

The same development of the importance of competence management can be identified for nonprofit organizations. The ARC Lower Austria wants to establish such a system to know about additional competencies to be able to identify people within the organization who have particular skills, more than knowledge of "traditional" first aid. In this specific case volunteers generally think that the most required competence is knowledge of first aid, but still the ARC as an organization is always looking for people within the organization with further competencies. The results showed that only half of the volunteers were conscious that the ARC Lower Austria needs further competencies within the organization. This finding may apply to other (non profit) organizations that have a very clear image on the core competence, so that additional competencies not as a function of the core business are not considered. As the respondents of this case study were volunteers a very high intrinsic motivation can be assumed, which results in a very high percentage of respondents $(84,4 \%)$ willing to contribute with further knowledge. This specific characteristic mainly applies to other nonprofit organizations but probably not entirely to private organizations.

The positive appraisal and interest in participating in an expert group is very high within the ARC Lower Austria. The project team estimates this result as not only based on the fact that the ARC Lower Austria projects altruistic feeling, but also as a matter of organisational culture, which leads to the conclusion that an efficient organization and effective implementation of realized work of expert groups could provoke similar evaluation among employees of other organizations.

But still there are some restrictions as one of the main motivations for volunteering is the altruistic feeling helping others. A system that supports this motivation may have more success. As described in other studies, altruistic feelings and feelings of social recognition could stimulate higher membership levels in the organization [13]. This implies that the majority of the results are highly adaptable for other nonprofit organizations, but within organizations with low altruistic motivation and for example high profit-orientation restrictions of these results should be considered.

\section{References}

[1] Aguado, A. (2009). Teaching Research Methods: Learning be Doing. Journal of Public Affairs in Education. 15(2), pp. 251-260.

[2] Andeßener, R., Besonderheiten im Kompetenz- und Wissensmanagement in Nonprofit-Organizationen. In R. Zaugg (Ed.), Handbuch Kompetentmanagement (pp. 363370). Bern: Haupt Verlag, 2006.

[3] Alavi, M. \& Leidner, D.E. (2001). Review: Knowledge Management and Knowledge Management Systems: Conceptual Foundations and Research Issues, MIS Quarterly, 25(1), pp. 107-136. 
[4] Ball, C., \& Pelco, L. (2006). Teaching Research Methods to Undergraduate Psychology Students Using an Active Cooperative Learning Approach. International Journal of Teaching and Learning in Higher Education, 17(2), pp. 147-154.

[5] Barraket, J. (2005). Teaching Research Method Using a Student-Centred Approach? Critical Reflections on Practice, Journal of University Teaching \& Learning Practice, 2(2), 2005. pp. 64-74.

[6] Draganidis, F. \& Mentzas, G. (2006): Competency based management: a review of systems and approaches, Information Management \& Computer Security, vol. 14, No. 1, pp. 51-64

[7] Fearon, C., Starr S. \& McLaughlin H. (2011). Value of blended learning in university and the workplace: some experience of university students. Industrial and Commercial Training, 43(7), pp. 446-450.

[8] Heinsman, H., de Hoogh, A., Koopmann, P., van Miujen, J. (2008): Commitment, control, and the use of competency management, Personnel Review, Vol. 37, No. 6, pp. $609-628$.

[9] Hendrickson, A.R. (2003). Human Resource Information Systems: Backbone Technology of Contemporary Human Resources, Journal of Labor Research, 24(3), pp. 381-394.

[10] Ley, T., Organizational Competency Management: A Competence Performance Approach - Methods, Empirical Findings and Practical Implications, Shaker, 2006.

[11] Mindel, J. L. \& Verma, S. (2006). Wikis for Teaching and Learning. Communications of the Association for Information Systems. 18(1), pp. 2-38.

[12] Minocha S. \& Roberts D. (2008). Social, usability, and pedagogical factors influencing student's learning experiences with wikis and blogs. Pragmatics \& Cognition, 16(2), pp. 272-306.

[13] Troy, L. C., \& Paswan, A. K. (2004). Non-profit organization and membership motivation: an exploration in the museum industry. Journal of Marketing Theory \& Practice, 12(2), pp. 1-15.

[14] Ulrich, D. O. \& Lake, D., Organizational Capability: Competing from Inside Out. Canada: John Wiley \& Sons, 1990. 